\title{
DIREITO E SUBJETIVIDADE: UM ENSAIO SOBRE O PODER DE PUNIÇÃO DO ESTADO
}

\author{
Érica Babini Lapa do Amaral Machado ${ }^{1}$ \\ João Paulo Allain Teixeira²
}

\section{Resumo}

O presente ensaio pretende compreender em que medida existem espaços políticos (escolhas subjetivas) no processo de decisão judicial, discutindo as formas de controle desta dimensão subjetiva para a garantia democrática do respeito à autonomia humana. Para isso, resgata valores fundamentais da modernidade, tais como: segurança e promessa de justiça, fundamentos da racionalidade instrumental que são, em grande medida, legitimadores da dogmática como ferramenta única para decisões de conflitos sociais. A blindagem decorrente daquelas promessas, contudo, é apenas uma forma de encobrir decisões subjetivadas, condicionadas por relações sociais estruturadoras, sendo indissociáveis poder político e força. Essa relação é claramente perceptível no Direito Penal, cujas construções históricas e contemporâneas dos institutos da pena e do processo são resultados de demandas oriundas das esferas econômica e política. Com o inevitável reconhecimento do espaço da política no Direito, os autores travam uma discussão sobre os elementos que, eventualmente, contribuam para o controle dessa subjetividade.

Palavras-chave: subjetividade; modernidade; dogmática; economia política da pena

\section{INTRODUÇÃO}

Trata-se de artigo em que se pretende desconstruir a racionalidade como imperante na metodologia central do processo de conhecimento e abrir espaços para o reconhecimento de subjetividades no processo decisório, impondo assim, novas técnicas jurídicas de controle dessas subjetividades.

Para esse fim, pretende-se compreender a estrutura de legitimação da dogmática no espaço da modernidade e as consequências do império da autoridade da lei, sem possibilidade de interseções subjetivas de

\footnotetext{
${ }^{1}$ Doutora pela Universidade Federal de Pernambuco - UFPE. Professora de Direito Penal e Criminologia da Universidade Católica de Pernambuco. Pesquisadora do Grupo Asa Branca de Criminologia. E-mail: ericababini@hotmail.com

2 Doutor em Direito pela Universidade Federal de Pernambuco (2005). Professor Adjunto na Universidade Federal de Pernambuco, Professor Assistente na Universidade Católica de Pernambuco. Avaliador "ad hoc" do Instituto Nacional de Estudos e Pesquisas Educacionais Anísio Teixeira (INEP) do Ministério da Educação (MEC). Membro da Comissão de Qualificação de Eventos para a área Direito da CAPES. Líder do Grupo de Pesquisa "Jurisdição Constitucional, Democracia e Constitucionalização de Direitos” no Diretório Geral de Grupos de Pesquisa CNPq. E-mail: jpallain@gmail.com
} vol. 08, nº. 04, Número Especial. Rio de Janeiro, 2015.pp. 2382-2401 
valores - escolhas políticas - as quais colocariam em risco toda aquela estrutura, porque fundada em imparcialidade.

Esse mecanismo, porém, é questionado por meio do Direito Penal (dogmática penal), o qual é historicamente utilizado para assegurar necessidades políticas de ordenação segurança e econômica de acumulação de riqueza.

Por fim, pretende-se perceber o grau do simbolismo do Direito e questionar (no âmbito do Direito Penal) em que medida a dogmática penal é capaz de domesticar os espaços da subjetividade no processo de interpretação e aplicação do direito. Caso essa tarefa não seja bem-sucedida, precisamos discutir então, os referenciais de justiça e democracia sobre os quais estão amparadas tais escolhas.

\section{RACIONALIDADE, DIREITO E MODERNIDADE: O DIREITO COMO SISTEMA ABSTRATO DE CONFIANÇA E ORDENAÇÃO}

A ideia de civilização - fruto dos engenhos do contrato social - é construída pela imposição de uma ordem, a qual traduz a promessa de segurança, pois a "ordem" (que implica regularidade e estabilidade, favorecendo a previsão e o controle dos acontecimentos) é necessária para afastar toda a instabilidade do passado - "de fato, pode-se definir a modernidade como a época, ou o estilo de vida, em que a colocação em ordem depende do desmantelamento da ordem tradicional, herdada e recebida" (BAUMAN, 1998, p. 20).

O projeto de modernidade, delineado a partir do século XVIII, é um esforço intelectual dos Iluministas para desenvolver a ciência objetiva, a moralidade e leis universais, em que o acúmulo de conhecimento, gerado na busca da emancipação humana, prometia a liberdade da escassez de todas as ordens, da cessação da arbitrariedade e das calamidades naturais. Além disso, o desenvolvimento das formas racionais de organização social e de modos racionais de pensamento permitia o fim da irracionalidade dos mitos, da religião e do uso arbitrário de poder (HARVEY, 1996, p. 23).

Nesse sentido, confiança (versus risco) e segurança (versus perigo) representam sentimentos de superação, garantidos pela construção das instituições sociais, de modo a favorecer as possibilidades (versus a sombra) diversas da instabilidade medieval. $\mathrm{O}$ mundo perfeito seria o que permanecesse sempre idêntico, ordenado e puro - as coisas colocadas em seus devidos lugares, de modo que, se são deslocadas tornam-se sujas, não porque o são, mas porque estão idealizadas em locais diferentes.

Para esse desiderato a ciência era a ferramenta capaz da contenção da natureza, justificada pela vontade de humanidade (oposto da natureza), onde os objetos (seja a planta que nasce no local desarmonioso, sejam os "débeis mentais" que não têm utilidade) devem ser meticulosamente analisados, de modo que comprometimentos à ordem sejam rejeitados. 
É que somente com a proposta de Descartes, do "verdadeiro método para chegar ao conhecimento de todas as coisas que meu espírito fosse capaz" (DESCARTES, 2001, p. 21), (adestração ao método) realizado por meio da observação controlada dos fatos, seria possível a ascensão ao ápice do conhecimento.

O sujeito é que conhece o objeto e define-o, explica-o. A razão, que diferencia o homem dos animais, por ser capaz de produzir conhecimento e de memorizar, classifica o mundo em entidades, formando estruturas aptas a manipular os acontecimentos em probabilidades, afastando as causalidades (BAUMAN, 1999, p. 9). É ela, a razão, tomada como a chave de todos os problemas.

Assim, considerando a racionalidade funcionar como o controle da narrativa para o oferecimento de segurança, isto é, o impulso explicativo que circunscreve o desconhecido, construindo referenciais, a fim de que o método impere para potencializar a universalização da ciência, nada mais natural que o ideal moderno tomar a racionalidade como única ferramenta apta a pensar e compreender a realidade, desqualificando quaisquer outras.

É assim que o paradigma dominante da racionalidade, presente desde a revolução científica do século XVI, foi levado às ciências sociais no século XIX, perfazendo-se como modelo totalitário, posto que só seria científico aquele saber que se ajustasse aos princípios epistemológicos e regras metodológicas. Afinal, "ordem e estabilidade do mundo soa a pré-condição da transformação tecnológica do real” (SANTOS, 1998, p. 16).

Assim, o pensamento lógico, matemático e as estratégias empiristas se impuseram na busca da verdade objetiva, fundada na evidência racional, figurando como primeiro princípio cartesiano "jamais aceitar alguma coisa como verdadeira que não soubesse ser evidentemente como tal" (DESCARTES, 2001, p.9).

De acordo com o contexto, esse fundamento da razão humana como elemento central da organização social, ensejou significativas modificações no plano do Direito; basta perceber a Declaração Universal dos Direitos do Homem - o direito natural foi o sustentáculo jurídico de limitação do Estado, de eliminação dos privilégios da nobreza e do clero (que nada tinham de racionais).

Ao longo da era moderna, a razão legislativa dos filósofos convergiu para as práticas materiais do Estado, voltadas à transformação das sociedades ordeiras. Ao Estado jardineiro ${ }^{3}$ cabia projetar a sociedade ditada pela suprema e inquestionável autoridade da razão, substituindo aquelas outras sociedades consideradas ainda no estado da natureza, haja vista ser este o único mecanismo capaz de assegurar, imparcialmente, a estabilidade.

Coube à certeza racional empreender a secularização do pensamento filosófico e científico, separando a certeza imotivada da fé, tudo analisado com base na evidência. Assim, o novo modelo de perceber a história, em que o presente ultrapassa o passado e é o sinônimo de bom, pois é a luz da saída da caverna que se impõe linearmente - como a única forma correta de conhecer o mundo; e como conhecimento verdadeiro não pode ser

\footnotetext{
3 "Ele deslegitimou a condição presente (selvagem, inculta) da população e desmantelou os mecanismos existentes de reprodução e autoequilíbrio. (BAUMAN, 1999, p. 29).
} 
contestado. Com o tempo, a tendência da monopolização da fonte do Direito pelo Estado tornou-se onipotente com a codificação

Com a formação do Estado moderno, o direito natural e o positivo não são mais considerados como do mesmo nível, eis porque sobretudo o direito positivo (como direito posto e aprovado pelo Estado) é tido como o único e verdadeiro direito: esse é o único a encontrar, doravante, aplicação nos tribunais (BOBBIO, 1995, p. 23).

Naturalmente, o Direito passou a ser manejado como uma ferramenta a serviço dos interesses políticos do Estado, especialmente o Direito Penal, que foi usado como "um dos mais importantes instrumentos de imposição de sua autoridade, e ao mesmo tempo como máquina protetora da ordem social estabelecida" (TOMÁS Y VALIENT, apudFREITAS 2001, p. 35).

Enfim, é o triunfo da visão estatalista que tem como única fonte legitima do Direito o aparelho estatal. Ou seja, o Direito se resume à lei, cuja única fonte é o Estado

A sobreposição da força de lei se dá porque sendo a racionalidade um critério objetivo, ela representa imparcialidade, isto é, a razão utilizada nos julgamentos, com uso dos silogismos, significa decisões puramente baseadas na vontade da lei que por si éa representação democrática do povo. Por via de consequência, a decisão se torna inquestionável. Ou seja, a razão baseia-se em abstrações, e por isso produz conhecimento formal e impessoal, razão pela qual o político, expresso na subjetividade, é aniquilado pelo jurídico, uma operacionalização que decorre do conhecimento das regras técnicas.

Enfim, como se apresenta, a marca constante do que se denomina de modernidade é o grau de generalidade que se imprime aos conceitos, como slogans, funcionando independente das experiências concretas e, dado o complexo grau das estruturas econômicas que se avultava, essa seria a melhor estratégia de assegurar o desenvolvimento rumo ao futuro, que a ciência prometia e as expectativas sociais ansiavam. Não é sem razão que o movimento de codificação e constitucionalização tem seu início no desejo burguês de generalidade e impessoalização.

É comum se compreender a força do Direito, que se impõe sem reticência social, onde os súditos cumprem obedientemente suas prescrições, residente na justiça que ele expressa e promete realizar. Em razão da expectativa da justiça, a norma se valida, e tudo o que dela decorre - sobretudo a força - é um exercício legítimo da autoridade. Por isso, a força é "essencialmente implicada no próprio conceito de justiça enquanto direito" (DERRIDA, 2010, p. 8).

Conhece-se que Direito e força se ligam de maneira inevitável, pois não há direito que não implique ele mesmo, "a priori, na estrutura analítica do seu conceito, a possibilidade de ser 'enforced', aplicado pela força" (DERRIDA, 2010, p. 8). Entenda-se por força “sempre de força 'performativa', força ilocucionária ou perlocutória, força persuasiva e de retórica, de afirmação da assinatura, mas também e sobretudo de todas as situações paradoxais em que a maior força e a maior fraqueza permutam-se estranhamente" (DERRIDA, 2010, p. 11). 
Nesse sentido, a instituição de uma ordem jurídica, como uma decisão, por exemplo, nunca é um ato de violência, pois realizada por uma autoridade que atua em nome da justiça, o que há é exercício legítimo de poder. Isto é, o Direito é separado de violência e fundado na justiça, de modo a se confundirem e ser inquestionável qualquer de suas intervenções.

Nesse contexto, a ciência jurídica constrói uma autonomia absoluta a partir de teorias que a libertam do peso social, regras que são independentes das pressões sociais, como um sistema fechado. "Um universo social autônomo, capaz de produzir e reproduzir, pela lógica de seu funcionamento específico, um corpus jurídico relativamente independente dos constrangimentos externos" (BOURDIEU, 2010, p. 215)4.

Dessa forma, existe um monopólio, por parte dos juristas, da capacidade de dizer o direito. Os agentes, investidos de competências têm a legitimidade de interpretar, o que, além de fundamentar a cisão com os leigos e condensar a racionalidade, aumenta a independência que consagra o Direito. Além do mais, as instâncias hierarquizadas para resolver conflitos e interpretações, garantem a diferença da decisão jurídica de uma política, na medida em que aquela "se apresenta como resultado necessário de uma interpretação regulada de textos unanimemente reconhecidos" (BOURDIEU, 2010, p. 214), e não resultado de escolhas.

Esse mecanismo, descreve Bourdieu, é essencialmente a coesão do habitus, uma categoria sociológica que consiste em um sistema de disposições duráveis, "estruturas estruturadas" predispostas a funcionar como "estruturas estruturantes", isto é, como princípio de geração e estruturação de práticas e representações que podem ser objetivamente "regulamentadas" e "regular" sem que o produto - obediência a regras - seja assumido conscientemente, mas que, ao final das contas, visa ao controle de operações específicas necessárias para atingir determinado objetivo (BOURDIEU, ApudVILLEGAS, 2004, p. 57).

A elaboração de regras e procedimentos com postura universalizante, em que a equidade se baseia na dedução daqueles, é o fundamento de coerência interna que forma o capital específico do sistema jurídico e, além disso, é o próprio habitus que consiste na elaboração dos operadores do direito e dos teóricos que, apesar de aparentemente antagônicos, possuidores de capital jurídico diferente, exercem função de complementariedade no sentido de fortalecer a "cadeia de legitimidade, subtraindo os seus actos ao estatuto da violência arbitrária" (BOURDIEU, 2010, p. 220).

A judicialização funciona como lugar neutro e, por isso, neutraliza o que está em jogo, pois os agentes especializados introduzem uma distância dos objetos, que é, em si, um imperativo no âmago do habitus que se concretiza na luta do poder de nomear e ordenar o mundo, definindo a normalidade de suas atitudes.

\footnotetext{
$4^{4}$ o efeito de apririozação que está inscrito na lógica de funcionamento do campo jurídico, revela-se com toda a clareza na língua jurídica que, combinando elementos retirados da língua comum e estranhos ao seu sistema, acusa todos os sinais de uma retórica da impessoalidade e da neutralidade, efeitos estes que são adquiridos por características sintáticas de construção". (BOURDIEU, 2010, p. 215).
} 
A convergência se identifica exatamente na necessidade de conservação que o próprio Direito se impõe, repelindo as compreensões plurais e individuais, por ameaçarem a própria existência do Direito. A conservação se dá exatamente na realização do habitus, que por si mantém a distância entre as partes, neutralizando a relação e normalizando as nomeações jurídicas, em nome da doutrina, da jurisprudência etc.

Nas palavras de Derrida, é do interesse do Direito, que se instaurou por um ato de violência, conservar-se, ainda que pelo mesmo meio, de modo que exclui mesmo as violências individuais, por ameaçarem sua ordem, razão pela qual o Direito monopoliza a violência, não para proteger fins justos e legais, mas para se autoproteger (DERRIDA, 2010, p. 78).

É nesse sentido que o Direito se mantém como força performativa e de repetição, a fim de conservar, prometendo, e, porque inscrita numa lei de iterabilidade ${ }^{5}$, mantém-se, ainda que a promessa não seja cumprida. Na verdade, a instauração do Direito já é iterabilidade, apelo à repetição autoconservadora, a qual é refundada para poder conservar o que pretende fundar. Enfim, "enquanto meio, toda violência funda ou conserva o direito. Não há problemática do direito sem essa violência dos meios. Sem esse princípio de poder" (DERRIDA, 2010, p. 109).

Portanto, a legislação que, violentamente, se funda e se conserva, é feita pelos juristas no momento da interpretação, mantendo, ainda que com renovações, a sua estrutura.

Essas considerações da formulação do Direito adapta-se às exigências de imparcialidade e neutralidade do jurista; pretensões modernas de ordem e segurança, o qual não deve agir balizado por pressões externas, muito menos por escolhas pessoais. Ao revés, a batuta do Direito está na norma, uma elaboração teórica que é reflexo do consenso e, por isso mesmo legitima, a impor - como violência admitida - suas ordenações, e a prescrever comportamentos no mundo privado de cada homem que esteja sob sua égide.

Não obstante, esse sistema é garantido por um aparato de força física que garante as prescrições comportamentais, e, por via de consequência as necessidades modernas de contenção de todos os perigos que ameacem a estabilidade.

\section{MONOPÓLIO DA VIOLENCIA ESTATAL E O DIREITO COMO PODER SIMBÓLICO: A FORMAÇÃO DE ESTRUTURAS ESTRUTURANTES}

É importante compreender o porquê da racionalidade instaurar-se como metodologia central do processo de conhecimento. Ao defender que a cultura é resultado de um processo de dominação realizado pela classe dominante, que cria a falsa ideia de uma sociedade integrada, cujo efeito ideológico é dissimular a divisão de

\footnotetext{
${ }^{5}$ A noção de iterabilidade proposta por Jacques Derrida significa que o sujeito pensado em um horizonte de linguagem, ou seja, um sujeito enunciador de um texto será repetido mesmo depois de sua morte. O momento da imanência da criação de um texto, que para Jacques Derrida é uma cena originária, é apenas um marco já destinado à transcendência através da repetição (iterabilida de) para o outro (alteridade). (SANTOS, 2011)
} 
classe (BOURDIEU, 2010), Bourdieu afirma que, sob os influxos da definição cultural de um tempo, irrompem fatores de ordem econômica que, ao dissimularem-se de cultura, determinam as suas direções políticas como se fosse expressão de uma coletividade, que não o é.

Desse modo, é imperioso perceber que "as leis não são justas como leis. Não obedecemos a elas porque são justas, mas porque têm autoridade, a qual repousa no crédito que lhe concedemos" (DERRIDA, 2010, p. 21), isto é, a fundação do Direito é mitológica ${ }^{6}$. No entanto, esse fundamento místico da autoridade tem que ser escamoteado, e até mesmo construído, pois identificar o que é valorativamente justo ou não decorre de uma escolha política ou moral, e isso seria o próprio direito atestar seu óbito, pois fugiria à justiça que pretende fazer, com base na lei.

É nesse sentido que é possível perceber as relações entre Economia e Direito. Capitalismo e industrialismo, como feixes organizacionais que se relacionam diretamente no desenvolvimento das instituições modernas, em que, de um lado o capitalismo institui um sistema de produção de mercadorias, centrado sobre a propriedade privada do capital e do trabalho assalariado; e do outro, o industrialismo acrescenta a maquinaria no processo de produção de bens; impõem como consequência desta interação expansão e ordenação, que demandadas em nome da competitividade, necessitam de ordem para se realizar - surgem aí as relações jurisdicionalizadas (GIDDENS, 1991, p. 63).

Aliás, aqui se percebe claramente a adequação sociológica de Bourdieu ao se referir que "as ideologias devem a sua estrutura e as suas funções às condições sociais da sua produção, às funções que elas cumprem (...) que é produzir formas eufemizadas das lutas econômicas e políticas entre as classes" (BOURDIEU, 2010, p. 1314). Isto é, tornar natural o processo de dominação.

É nesse sentido que a concentração administrativa, necessária para a produção dos postulados industriais e capitalistas, instituiu condições de vigilância bem além daquelas das civilizações tradicionais, de modo que o monopólio bem-sucedido dos meios da violência repousa sobre os códigos criminais como o "supervisor de desvios" (GIDDENS, 1991, p. 65), daqueles que não se sujeitam à demanda.

No entanto, essa interpretação importaria espaços de subjetividades, escolhas pessoais (definir como desviante apenas as condutas de alguns), o que colocaria em risco a legitimidade - que se baseia na imparcialidade. Essa construção hipostasiada do Direito não questiona, por exemplo:

Se a justiça não é necessariamente o direito ou a lei, ela só pode tornar-se justiça, por direito ou em direito, quando detém força, ou antes, quando recorre à força desde seu primeiro instante, sua primeira palavra, pois a justiça sem força é contradita, porque sempre há homens mas, a força sem justiça é acuada (DERRIDA, 2010, p. 17).

\footnotetext{
${ }^{6}$ A constatação de que a justiça não possui um status metafísico puro e de que seu estabelecimento se liga a forças reais, isto é, forças econômicas e políticas, fazem com que, para Derrida, tanto a filosofia de Pascal quanto a de Montaigne possam ser consideradas um prelúdio da filosofia crítica moderna, ao realizarem, de certa maneira, uma crítica da ideologia jurídica.
} vol. 08, nº. 04, Número Especial. Rio de Janeiro, 2015.pp. 2382-2401 
Admitir escolhas políticas implica pôr em xeque a legitimidade da violência e a proposta racional da modernidade, nas suas medidas do justo e do injusto, passando a deixar transparecer que o Direito seria apenas reflexo de mera força, sem qualquer contingenciamento de justiça, confinando o sujeito em criteologias.

Contudo, sendo a justiça puro movimento, contê-la nas esferas rígidas do Direito é retirar a sua vitalidade, deixando, por isso mesmo, de ser justiça. Por isso que Derrida (2010) assume a justiça como uma experiência do impossível (BERCHT, 2010, p. 129), experiência porque pode ser experimentada, e impossível porque nunca se poderá fazer este experimento, ou seja, a justiça é um apelo à justiça, enquanto que o direito é um momento de cálculo de uma regra.

No entanto, esses questionamentos não são manejados, e as verdades mitológicas inquestionáveis do Direito terminam por cristalizar os juristas na autoridade da lei, o que em verdade não tem qualquer fundamento, pois não é ontológico ou racional, porque despido de explicação lógica. É, na verdade, a crença na autoridade da lei, um ato de fé, uma autoridade mística, isto é, apoia-se em si mesma, e por isso é uma violência sem fundamento.

Ou seja, as indagações críticas não são realizadas porque manter a solução dos conflitos fora dessa aleatoriedade é essencial para a sobrevivência do próprio Direito, especialmente no trabalho de racionalização. Ainda mais, autonomia professada pelo Direito e corroborada do ponto de vista interno por uma divisão de trabalho entre os juristas, assegura a cisão entre o leigo e o técnico, tornando esse o único capaz de resolver os conflitos particulares, desqualificando uma outra visão de mundo - de equidade - impondo a jurídica ${ }^{7}$.

Essa cadeia de legitimidade subtrai a arbitrariedade da violência (autoridade da lei) e reflete exatamente o Direito como poder simbólico.

\section{DIREITO COMO PODER SIMBÓLICO}

Poder simbólico é "um poder de construção da realidade que tende a estabelecer uma ordem gnosiológica: o sentido imediato do mundo" (BOURDIEU, 2010, p. 8). O poder simbólico é aquele que constitui o dado pela enunciação, fazendo ver e crer, confirmando ou transformando a visão de mundo, agindo sobre este próprio mundo. Ou seja, o poder simbólico é um sistema estruturado, que estrutura o conhecimento e o faz, por existir uma concordância mínima entre as subjetividades estruturantes - consenso. O poder simbólico somente é aceito como legítimo porque há uma crença entre aqueles que se submetem a este poder na crença de que ele éo único adequado para solução dos conflitos, mas sequer é tido como uma forma de força, de violência ou de poder.

\footnotetext{
7 "Austin admirava-se com o fato de que nunca se teria perguntado por que razão ' nós nomeamos coisas diferentes com o mesmo nome” (BOURDIEU, 2010, p. 226).
} 
O efeito específico de mobilização decorre desse reconhecimento e da ignorância da arbitrariedade, uma realidade que permite afirmar que o poder simbólico não reside nos sistemas simbólicos em si, mas nas relações determinadas entre os que exercem o poder e os que lhe estão sujeitos, como uma crença na legitimidade.

É por essa razão que o poder simbólico está em toda parte, mas não se apresenta como poder, ou porque é ignorado (mas reconhecido), ou porque é exercido, e sequer sem saber que o é (é desconhecido), mas está presente. É um "poder invisível o qual só pode ser exercido com a cumplicidade daqueles que não querem saber que lhe estão sujeitos ou mesmo que o exercem" (BOURDIEU, 2010, p. 8).

E, de fato, o Direito é mesmo a expressão clássica desse poder simbólico, como demonstrou Bourdieu, uma vez que o Direito nada mais é do que um campo de conflito entre juristas, para angariar a possibilidade última de dizer o Direito, uma luta que, na verdade, o é pela detenção do poder simbólico, e que ao mesmo tempo não é uma luta de antagônicos, mas uma relação de complementariedade - no universo do habitus.

Além disso, o Direito nomina o mundo quando da solução dos conflitos, amparado por categorias de neutralidade e imparcialidade, decorrentes da universalização das leis. Tudo isso significa uma estrutura estruturante que, purificando-se de qualquer injustiça e ilegitimidade, ganha ainda mais legitimidade, retroalimentando-se.

A interpretação jurídica encarrega-se de manter a altivez da impessoalidade, mediante técnicas de seleção de textos, teorias hermenêuticas autorreferenciais que são independentes do contexto sóciopolitico de onde se originaram, num contínuo processo de racionalização.

A proposta crítica de Bourdieu consiste em desmistificar as formas eufemizadas, mascaradas, do poder simbólico, como uma "tomada de consciência do arbitrário, revelando a verdade objetiva, aniquilando a crença" (BOURDIEU, 2010, p. 15), uma destruição das ortodoxias, algo que equivale à proposta de Jacques Derrida (2010) de romper com a realidade que não é realidade em si, mas uma construção desta realidade.

Essa compreensão externa - crítica - implica a abertura à essência da linguagem, os signos, e o reconhecimento das relações de alteridade nas soluções dos conflitos, em que a vida privada escapa à esfera do poder, o que seria inadmissível para o Direito, dada a ameaça que cria à sua conservação ${ }^{8}$. Sob esse ângulo da praticidade deve-se rejeitar toda a violência mítica que é fundadora do direito, assim como toda a violência conservadora que está à serviço da fundação do Direito, admitindo e reconhecendo espaços de subjetividade.

Destarte, é primordial desvendar a função política deste sistema simbólico, que não se reduz somente à função de comunicação, mas vai além. "Os símbolos são instrumentos por excelência de integração social (...) eles tornam possível o consensus acerca do sentido do mundo social que contribui fundamentalmente para a

\footnotetext{
${ }^{8}$ Nessa perspectiva, Derrida explica do porquê o direito moderno punir a mentira, pois esta é, de fato, uma ameaça individual à conservação do direito, de modo que deve limitar à pior violência por uma outra violência. 
reprodução da ordem social" (BOURDIEU, 2010, p. 10). Bourdieu apreende esta ideia e a isso soma uma espécie de homologia que significa as condições sociais da produção e circulação de ideologias. Isto é,

A função propriamente ideológica do campo de produção ideológica realiza-se de maneira
quase automática na base da homologia de estrutura entre o campo de produção ideológica
e o campo da luta de classes. A homologia entre os dois campos faz com que as lutas por
aquilo que está especificamente em jogo no campo do autônomo produzem
automaticamente formas eufemizadas das lutas econômicas e políticas entre as classes: é na
correspondência entre estrutura a estrutura que se realiza a função propriamente ideológica
do discurso dominante, intermediário, estrutura estruturante que tende a impor a apreensão
da ordem estabelecida como natural (ortodoxia) por meio da imposição mascarada (logo
ignorada) de sistemas de classificação e de estruturas mentais objectivamente ajustadas às
estruturas sociais (BOURDIEU, 2010, p. 13-14).

Nesse sentido, o sujeito não pode ser compreendido fora das condições econômicas em que ele atua, posto que as estruturas internas de sociologização somente funcionam na correspondência objetiva do mundo, uma relação que alimenta funções políticas, essenciais à sociedade. É por isso que os sistemas simbólicos são estruturas de dominação, pois o interno só é aceito se somente se corresponder ao externo (VILLEGAS, 2004), como um mecanismo de legitimação.

Por essa questão de correspondência é que Bourdieu (2010) tenta esclarecer que não é apenas a interseção de interesses dominantes que definem o conteúdo jurídico, mas é o conjunto de relações objetivas entre direito, poder e cultura em seu conjunto. Isso implica investigar elementos externos ao Direito, assim como internos.

Internamente porque a visão de mundo é semelhante entre aqueles que formam o habitus no campo jurídico, pois visam à manutenção do poder simbólico na mão daqueles que já dispõem, reforçado externamente (mas sem isso ser assumido) pelo uso do argumento de autoridade da jurisprudência? . Aliás, mesmo esse raciocínio interno apresenta uma escolha política, uma decisão individual se segue determinada corrente jurisprudencial ou não, e isto afasta a neutralidade pretendida pelo Direito, ainda que sob a roupagem de uma neutralidade.

Outrossim, a eficácia do Direito vai além daqueles que já detêm o poder simbólico. Atinge-na o leigo, posto que a eficácia simbólica não pode exercer-se sem a cumplicidade daqueles que a suportam ${ }^{10}$, num trabalho de normalização, o qual assegura as pretensões do poder simbólico que é exatamente impor suas representações conceituais no diferente, tendendo a parecer desviante, anormal, patológico, representações diferentes dos valores

\footnotetext{
${ }^{9}$ A referência, numa tomada de posição, ao corpo de precedentes, indicando que aquela decisão foi tomada no interior do próprio sistema jurídico - e não por uma escolha pessoal - reforça a racionalidade no sentido da aplicação neutra e objetiva de uma competência jurídica. É o que se faz, por exemplo, na recorrência às decisões do Supremo Tribunal Federal e do Superior Tribunal de Justiça, reforçado por esses tribunais na elaboração de súmulas, e pior, entre súmulas vinculantes. BOURDIEU, Pierre. A Força do Direito. In: Poder Simbólico. 13 eds. Rio de Janeiro: Bertrand Brasil, 2010, p.231.

10 "Uma das funções do trabalho propriamente jurídico de codificação das representações e das práticas éticas, é a de contribuir para fundamentar a adesão dos profanos aos próprios fundamentos da ideologia profissional do corpo dos juristas, a saber a crença na neutralidade e na autonomia do direito e dos juristas" (BOUDIEU, 2010, p. 244).
} 
estabelecidos por aqueles que detêm o poder simbólico, e ratificado por aqueles que se submetem. Mantém-se assim, um continuum da dominação econômica na definição jurídica.

O que se propõe, na pesquisa jurídica, é exatamente a desnaturalização dessas relações descobrindo-se "causas objetivas e das razões subjetivas que fazem as pessoas fazerem o que fazem, serem o que são, e sentirem da maneira como sentem. É dar-lhes, portanto, instrumentos para comandarem o inconsciente social que governa seus pensamentos e limita suas ações" (WACQUANT, 2002, p. 100).

Assim, tanto este objetivo de Bourdieu (2010) como a desconstrução de Derrida (2010) são propostas aproximadas ao processo de conhecimento de Foucault, o qual pretendeu investigar as formas que se instauraram como domínios de saber a partir das práticas sociais (FOUCAULT, 2009a).

\section{PODER SIMBÓLICO E SISTEMA PUNITIVO: ATENDENDO ÀS ESTRUTURAS ESTRUTURANTES - UM ESTUDO DA ECONOMIA DA PENA}

A análise que Michel Foucault (2009a) realiza sobre o processo de conhecimento tem como pressuposto ser o sujeito conhecedor socializado por diversas influências socais, econômicas, culturais e políticas, de modo que as práticas sociais engendrem os domínios do saber, fazendo aparecer novos objetos, novos conceitos, novas técnicas, como também novos sujeitos de conhecimento. Isto é, as verdades são construídas, inventadas. Assim, considera ele que o conhecimento está mais próximo das relações de poder e luta, do que da unidade e beatitude, exaltadas pelos filósofos ocidentais.

É por isso que "As condições políticas, econômicas de existência não são um véu ou um obstáculo para o sujeito de conhecimento, mas aquilo através do que se formam os sujeitos de conhecimento, e por conseguinte, as relações de verdade". Um exemplo disto é a formação do processo, enquanto mecanismo de produção da verdade, resultado do mito da tragédia de Édipo (FOUCAULT, 2009a, p. 27).

Os gregos operaram duas formas de disputa - a luta - que era desafiada por aquele que tinha razão no litígio, e portanto tinha segurança de propor o risco e não correr, e a outra - busca da verdade - como foi em Édipo. Naquela, o conflito era resolvido entre os contendores; nesta, há um jogo de verdades, cuja prevalência é de testemunhas que, ante a investigação do assassino de Laio, o antigo rei, afirmaram vários encaixes da tragédia: o abandono de uma criança por Jocasta, o acolhimento daquela pelo rei Políbio e o assassinato do Rei.

Todos esses mecanismos - explica Foucault - funcionaram como uma representação do quadro político que se instaurava na Grécia, especialmente a grande revolução para a conquista da democracia ateniense, onde o povo poderia opor a verdade aos seus próprios senhores. Uma conquista assegurada pela possibilidade de apoderar-se do Direito como forma de produzir a verdade que, na Grécia consistia na arte de persuadir, isto é, obter a vitória era uma forma de convencer as pessoas. 
Aqui, há demonstração de que a forma jurídica do inquérito, como mecanismo de busca da verdade, foi construída como uma necessidade política do momento, mas que estacionou ali mesmo e sequer chegou a desenvolver um conhecimento racional, ficando esquecido ao longo da história.

Na Alta Idade Média, prevalecia o Direito Romano sob o Direito Germânico, como o foi nos reinos merovíngios, e no império Carolíngio. No entanto, cada vez que esses embriões de Estado eram dissolvidos, o Direito Germânico era resgatado, e terminou prevalecendo por muito tempo como direito feudal, não utilizando quaisquer dos procedimentos de busca da verdade já narrados, e sim um novo - o sistema de prova, cuja prevalência era da força e não da verdade: "no velho direito de Borgonha do século XI, quando alguém era acusado de assassinato podia perfeitamente estabelecer sua inocência reunindo à sua volta doze testemunhas que juravam não ter ele cometido o assassinato" (FOUCAULT, 2009a, p. 59).

Explica Foucault que esse mecanismo foi criado para favorecer o sistema de acumulação de riqueza da Alta Idade Média, pois dada a escassa circulação de bens, a riqueza era assegurada por heranças ou, sobretudo, pela forma belicosa. Isto é, a guerra era a forma mais comum de enriquecimento, pois alguém que se instalasse em determinada terra ou saísse por derrota das armas, ou porque recebia uma quantia para isso - direito e guerra tinham fronteiras fluidas.

Dessa forma, o que importava, na verdade, era que a concentração de armas estivesse sempre na mão dos poderosos, e isso era mantido por meio da vitória. Por isso era importante que os poderosos controlassem os conflitos, evitando que eles se desenvolvessem espontaneamente entre os indivíduos, dado o risco de terem armas e ameaçarem suas propriedades, e por isso mesmo perderem riqueza (FOUCALUT, 2009a, p. 54).

Ocorre que essas práticas desaparecem no fim do séc. XII e são substituídas por novas formas, que consistem em uma nova forma de saber. Figuras como o Poder Judiciário, o procurador, representante do soberano lesado e a infração como lesão ao interesse soberano e ao próprio soberano, exigindo portanto reparação, surgem num novo contexto da Idade Média.

O pano de fundo político dessa transformação decorre do fato que as monarquias ocidentais, para acumular riquezas, precisavam de bens, os quais passaram a ser obtidos por meio das multas, estabelecidas em sentença, dado que a principal vítima de um conflito passa a ser o rei. Desse modo, a liquidação judiciária não pode ser dada pelo mecanismo da prova, tal como antes.

O inquérito foi resgatado do Império Carolíngio, bem como da própria Igreja; e consistindo na discussão de pessoas conhecedoras das tradições, foi o mecanismo de gestão mais apropriado para aquele desiderato de acumulação de capital. 
Como se observa, o inquérito não foi atingido por um progresso da razão, resultado natural de um sujeito se elaborando. Ao revés, foi toda uma transformação política que tornou o inquérito uma maneira do poder se exercer.

O mesmo se dá mais claramente, no final do século XVIII, quando se constitui a "sociedade disciplinar", a qual se realiza por dois fatos - a reforma dos sistemas judiciários e penais do mundo.

As arbitrariedades e desproporções realizadas pelo poder das monarquias absolutistas, em que crime e pecado se confundiam, passaram a ser objeto de profundas contestações num contexto de Iluminismo. E nesse sentido, Beccaria na França; e na Inglaterra Bentham e Brissot propuseram três princípios fundamentais no sistema teórico da lei penal: de que crime não é falta moral ou religiosa, de que as leis para serem boas devem ser úteis para a sociedade e como decorrência desses dois fatores, deve haver uma definição clara e simples do crime (princípio da legalidade).

Na medida em que há uma nova definição de crime, por conseguinte também o é o criminoso, pois ele perturba a ordem social, causando incômodo a toda sociedade, é um inimigo interno, como afirmou Rousseau ele rompeu com o pacto social. E exatamente por este contexto, a penalidade muda de configuração.

Nesse sentido, a deportação e os mecanismos de humilhação, os trabalhos forçados e a lei de talião são as penas por excelência no sistema teórico de utilidade de Beccaria e Bentham. Entretanto, não foi isto que aconteceu. Essas penalidades desapareceram rapidamente e "por volta de 1820, no momento da Restauração na França e na Santa Aliança na Europa, percebemos que o sistema de penalidades adotado pelas sociedades industriais em vias de formação (...) foi inteiramente diferente do que tinha sido projetado alguns anos antes (...) e foi substituída por uma que era mencionada de forma marginal: a prisão" (FOUCAULT, 2009, p. 83-84).

A pena de prisão generaliza-se no século XIX, desviando-se do estatuto teórico. Além disso, a legislação penal também se desvia do princípio da utilidade, ajustando-se ao indivíduo. Isto é, tem cada vez menos vista a defesa geral da sociedade e mais a reforma psicológica e moral das atitudes dos indivíduos, controlando não só o que fazem, mas o que podem fazer.

É aqui que se enquadra o conceito de sociedade disciplinar, em que a estrutura do panóptico ${ }^{11}$ desenvolvida por Bentham simboliza perfeitamente essa sociedade do controle.

O panoptismo é uma forma de poder que repousa, não mais sobre o inquérito, mas ao que Foucault denominou de exame, vigilância, pois "não se trata de reconstituir o acontecimento, mas de alguém que se deve vigiar sem interrupção e totalmente por alguém que exerce sobre ele um poder, e na medida que o vigia, constitui sobre ele um saber" (FOUCAULT, 2009b, p. 88).

\footnotetext{
${ }^{11}$ Panopticon era um edifício em forma de anel, no meio do qual havia um pátio com uma torre no centro. O anel se dividia em pequenas celas, que davam tanto para o interior como para o exterior, de modo que do centro do anel era possível vigiar todos os acontecimentos.
} 
No século XIX, inicia-se a reconstrução do homo economicus subjacente às leis férreas e mecânicas da economia ricardiana, que se apresentava na Inglaterra. As razões desta mudança? "Algumas são econômicas: tornar útil cada indivíduo e rentável a formação, a manutenção o armamento das tropas; dar a cada soldado, unidade preciosa, um máximo de eficiência” (FOUCAULT, 2009b, p. 157).

No contexto de ascensão burguesa, o importante era a constituição do proletariado, a transformação do trabalho em capital produtivo de mais-valia. É por isso que o cárcere imputará duas identidades ao homem desvirtuado - leia-se - aquele praticante das ilegalidades populares que afetam os bens patrimoniais da burguesia ascendente: a identidade do criminoso-internado e a do não-propriteário-internado. Na verdade, equipare-se o delinquente ao preso, que passa a ser observado, porque perigoso, para que se transforme em um dever ser - cujo modelo é o homem proletário.

É o cárcere, portanto, o modelo do empresário

Isolamento absoluto do internado-trabalhador sublinha a vontade burguesa do operário sozinho, ou seja, não organizado. O momento disciplinar, juntamente com a falta de concorrência, oferecem ao empresário a mais absoluta disponibilidade de utilização da força de trabalho: a força do trabalho, disciplinada e violentamente "abstrata" pelo jogo do mercado livre, apresenta-se como fator "não-problemático" da produção. A reformation do internado encontra, como parâmetro de avaliação, além de outras formas externas de sujeição à autoridade, a produção quantitativa de mercadorias na unidade de tempo; emerge a ideia do operário remunerado não "por jornada", mas sim "por empreitada". A dependência absoluta (mais existencial do que real) do "não proprietário-criminoso-prisioneiro - do "proprietário-empresário torna-se manifesta; ao contrário do mundo da "produção livre, esta dependência/sujeição do proletário para com o capital será real, mais exatamente no e com o trabalho assalariado (MELOSSI; PAVARINI, 2006, p. 225).

Na verdade, o modelo celular representa o melhor instrumento para transformar o homem real, dotado de especificidades em homem virtual, em sujeito abstrato, sem emoções sem relação com o social, completamente dependente da soberania administrativa, uma forma moral de proletário que é imposta como única condição existencial, como única condição de sobrevivência do não-proprietário. Isto é, forjam-se na penitenciária indivíduos predispostos a obedecer, seguir ordens e respeitar ritmos de trabalho regulares, interiorizando a concepção capitalista de tempo como medida do valor. Essa "tecnologia do controle disciplinar que age sobre o corpo para governá-lo enquanto produtor de mais-valia e que, juntamente com outros corpos" cientificamente organizados, torna-se capital" (DI GIORGI, 2006, p. 45).

$\mathrm{Na}$ perspectiva da penalidade, Foucault procura mostrar como o papel da repressão vai mudando ao longo da história, deixando de assumir a publicidade da violência a que está ligada, uma vez que o suplício, reconhecido como dor, e seus executores como castigadores, passam a ser substituídos pela pena, em que os juízes ao aplicar a pena, não visam à punição, mas "o essencial é procurar corrigir, reeducar, curar [...] uma ortopedia moral" (FOUCAULT, 2009b, p. 15). 
Demonstram Rusche, G; Kirchheimer (2008) que, numa economia servil, os mecanismos punitivos desempenharam o papel de trazer mão de obra suplementar e construir uma escravidão civil, ao lado da fornecida pela guerra e pelo comércio, já no feudalismo, quando a moeda e a produção estão pouco desenvolvidas, há um crescimento dos castigos corporais, pois o trabalho obrigatório e a manufatura apareciam com o desenvolvimento dos primeiros comércios, o que muda lentamente com o sistema industrial, que demanda um mercado de mãode-obra livre, o que implica a mudança da punição sobre o corpo para a correção.

Aqui restou claro que o cárcere tem um objetivo muito preciso: reafirmação da ordem social burguesa, em que se deve educar o criminoso a ser proletário não perigoso, isto é, proletário sem ameaçar a propriedade. $\mathrm{Ou}$ seja, o “interior' surge como modelo ideal daquilo que deve ser o 'exterior' " (MELOSSI; PAVARINI, 2006, p. 217).

Inquérito e exame, assim como cárcere e fábrica são formas de saber-poder que funcionam como forma de apropriação de bens na sociedade feudal, e em nível da sociedade capitalista, condição de sobre-lucro. Aliás, a história do Direito Penal e das ciências não são séries separadas que, em algum momento da história, se encontram, ao revés, o corpo, nesse processo de formação epistemológico, é investido pelas relações de poder, que abriga a tecnologia do saber.

Enfim, a partir destas descrições históricas de Foucault, percebe-se claramente que a definição de penas foi condicionada pela estrutura social e econômica que se impunha, funcionando exatamente como relatou Bourdieu (2010) - estrutura estruturante é que define questões do Direito - que mantém aquela por funcionar como uma poder simbólico, ocultando violência fundante em nome de uma "justiça” que promete realizar; o que Derrida nomeia de fundação mitológica do Direito.

\section{A ESTRUTURAÇÃO DA HOMOLOGIA: UM EXEMPLO PARA SE PENSAR}

Vistas as questões, percebe-se que o projeto da modernidade na configuração de segurança e controle, valeu-se da ciência (saber) como a ferramenta mais apta para ofertar aquelas demandas. Neste sentido, a razão exerce até hoje papel de eixo central de um sistema que promete beleza, ordem, controle - um futuro linearmente definido, tudo construído a partir de uma tentativa de capturar as descontinuidades da natureza e da história humana.

O Direito, expressão da racionalidade para o cumprimento da justiça, é exatamente o artifício dessas pretensões modernas. Ou seja, a modernidade com o raciocínio otimista do tempo humano é instrumentalizada pela burocracia, favorecedora da técnica, protegida pelo modelo global de racionalidade. Assim, fundado na realização da justiça, o Direito vale-se da força para garantir aquela pretensão, imunizando-se de qualquer vestígio de arbitrariedade. 
No entanto, esse habitus jurídico, em que se reifica a técnica do Direito como a única capaz de solver conflitos, obstrui outras formas, como a equidade. Todavia aquele discurso permanece em nome da segurança que oferece em razão da imparcialidade que maneja.

Ocorre, porém, que o Direito é condicionado por "estruturas estruturantes" que condicionam seu exercício, ao mesmo tempo em que esse mesmo habitus jurídico é também uma estrutura estruturante, no efeito normalizador face à sociedade que regula.

Foucault demonstra bem esses condicionamentos descrevendo a economia da pena e as formas de resolução de conflito. Ou seja, o próprio saber é construído e condicionado por elementos econômicos, culturais e políticos, e por via de consequência, é fácil perceber que o Direito é resultado de uma séria de fatores externos, reproduzindo-os em sua própria estrutura, e mantido pelos próprios operadores, que assim o fazem na manutenção do poder simbólico que representa o ofício em que atuam.

É exatamente o efeito de homologia a que se referiu Bourdieu (2010) - as condições socioeconômicas, como estrutura estruturante, definem a prevalência de uma ou outra técnica jurídica, como demonstrou Foucault ante a preponderância, entre o duelo, o inquérito ou a prova, conforme a necessidade de verdade, força social ou acúmulo de riqueza; e os operadores do Direito, para a manutenção do poder simbólico reproduzem-nas, no mesmo efeito de homologia, independente de qualquer legalidade, a qual funciona apenas como argumento retórico de justificação para manter a base legitimadora do próprio Direito, que é a imparcialidade e segurança que promete.

Para exemplificar esse efeito de homologia em cascata, chamemos assim, resgatando para o hoje o entrelaçamento entre Bourdieu (2010), Foucault (2009ª) e Derrida (2010), utilizemos a jurisprudência.

O Superior Tribunal de Justiça (STJ) negou seguimento ao pedido de habeas corpus em favor de acusado de liderar tráfico na Baixada Santista. Ronaldo Duarte Barsotti de Freitas, conhecido como Naldinho, foi preso na operação Indra, do Departamento de Investigações sobre Narcóticos da Polícia Civil de São Paulo, em junho de 2005.

Ronaldo é acusado de posse ilegal de armas de fogo de uso permitido, de uso restrito e com numeração suprida, de munições, metralhadoras, silenciadores, carregadores e outros acessórios, além de grande variedade de entorpecentes. A defesa pedia o trancamento da ação penal. Alegou, para tanto, que a apreensão das armas, entre os dias 6 e 15 de junho de 2005, foi durante a abolitio criminis temporária (período que a lei não abrange) do Estatuto do Desarmamento, já que o prazo de entrega das armas de fogo à autoridade policial foi estendido até o dia 31 de dezembro de 2008. Assim, alegando falta de justa causa, a defesa pediu o trancamento da ação penal em relação aos delitos de posse, registro e comercialização de armas e munição.

O relator, ministro Og Fernandes, já havia negado o mesmo pedido em recurso de habeas corpus interposto pelo próprio Ronaldo. No recurso, o ministro afirmou que, quando há apreensão de arma ou munição dentro do período em que o Estatuto do Desarmamento ainda não estava em vigor, o STJ reconhece a descriminalização da conduta. Mas, neste caso, o local, a forma e a grande quantidade e variedade de armas e drogas apreendidas impossibilita a aplicação da abolitio criminis temporária (BRASIL, 2010). 
O Superior Tribunal de Justiça negou o writ de crime relativo a porte de arma de fogo de uso permitido e outros semelhantes, tipificados no estatuto do desarmamento, mesmo reconhecendo a abolitio criminis temporária desses delitos, argumentando que a negativa se dava pelo fato de o sujeito ativo ser traficante da baixada santista.

Julgando o mesmo crime, relativo ao mesmo período, o Tribunal concedeu o habeas corpus, por se tratar da incidência da abolitio criminis temporária, causa de extinção de punibilidade. Mas, agora, tratava-se de sujeito ativo diferente. Um professor de Educação física, árbitro de jogos de tênis de mesa.

HABEAS CORPUS. PENAL. ESTATUTO DO DESARMAMENTO. ARTIGO 16, CAPUT, DA LEI N. 10.826/03. ABOLITIO CRIMINIS TEMPORÁRIA. EXTINÇÃO DA PUNIBILIDADE.

1. Diante da literalidade dos artigos relativos ao prazo legal para regularização do registro da arma (artigos 30, 31 e 32 da Lei 10.826/2003), ocorreu abolitio criminis temporária em relação às condutas delituosas concernentes à posse ilegal de arma de fogo e de munições.

2. Ordem concedida para, a teor do que dispõe o art. 107, inciso III, do Código Penal, declarar extinta a punibilidade do Paciente quanto ao delito capitulado no art. 16, caput, da Lei n. ${ }^{\circ}$ 10.826/2003 (BRASIL, 2011).

O que se pretende demonstrar aqui, é que há uma estrutura social que condiciona, de alguma forma, a atuação do Poder Judiciário na figura de seus representantes, e neste caso é a guerra declarada contra as drogas, em que a opinião pública deposita na política criminal, nos crimes e castigos, todas as esperanças de erradicação do uso de drogas. Afinal, os juristas - na manutenção do poder simbólico usam o habitus para reforçar a estrutura do próprio Judiciário e a assunção de subjetivismos e de fatores de pressão social, econômica etc - são neutralizados pela imparcialidade.

Nesse sentido, a vontade de verdade, que atravessa vários séculos, imprime um sistema de exclusão pelo discurso $^{12}$, pois este ato de falar, cuja produção é ao mesmo tempo controlada, selecionada, organizada e redistribuída por certo número de procedimentos, e neste caso os sujeitos que falam são os técnicos. E aqui não importa que a fala seja verdadeira, mas o correspondente aos anseios dominantes, ou diria Bordieu - manutenção do poder simbólico. "O sofista é exaltado" (FOUCAULT, 2010, p. 35).

A relação entre discurso e poder e a construção discursiva de sujeitos sociais são elementos essenciais que destacam a interseção de subjetivos na prática da racionalidade, de modo que o espaço para as escolhas é inevitável.

Nesse diapasão, os condicionamentos não são apenas unilaterais, como demonstrou Foucault estrutura que condiciona os sujeitos, mas em termos de dialética, em que, há uma interação entre a prática discursiva e a realidade pré-constituída, num amoldamento recíproco, isto é, sujeitos não simplesmente assujeitadas, mas capazes de também remodelar e reestrutar as práticas discursivas, apesar de modelados.

\footnotetext{
${ }^{12}$ Considere-se discurso como "uso da linguagem como forma de prática social, um modo de ação, uma forma em que as pessoas podem agir sobre o mundo e especialmente sobre os outros, como também um modo de representação”. (FAIRCLOUGH, 2008, p.91)
} 
Destarte, a racionalidade, e todas as ferramentas que dela derivam, entre elas, a imparcialidade, extirpando juízos de valor, cai por terra, pois os discursos emergem de uma prática social que está firmemente enraizada em estruturas materiais concretas - econômicas, políticas,culturais, ideológicas etc. Desse modo, as ordens de discurso - facetas discursivas das ordens sociais, cuja ordem sofre a rarefação de um processo de controle, o qual é orientado para determinado fim - da racionalidade moderna que estabeleceu os princípios reguladores para a análise "o acontecimento à criação, a série à unidade, a regularidade à originalidade e a condição de possibilidade à significação" (FOUCAULT, 2010, p. 54), são questionadas.

Se assim o é, a interpretação e a aplicação do Direito, que se fundamenta na representatividade popular consubstanciada na norma, portanto imparcial, também está submetida a esse mecanismo. Por via de consequência, o conteúdo de uma lei - por si complexo e heterogêneo, de modo que os textos em geral são ambivalentes e abertos a múltiplas interpretações - é definido pelos intérpretes por um sentido conforme a prática social, ou seja, conforme as relações de poder etc.

Enfim, a definição do discurso do que é verdade ou não, é uma escolha, de fora mesmo já se estabelece qual é a verdade, pelo manejo dos instrumentos de controle do discurso. Os sujeitos estão submetidos a uma ideologia estrutural que orienta o discurso, reificada quando atinge o status de "senso comum", direcionada a determinada hegemonia, que nada mais é do que "liderança, tanto quanto dominação nos domínios econômico, político, cultural e ideológico de uma sociedade" FAIRCLOUGH, 2008, p. 123) que tende a manter as coisas como estão a modificá-las, reestruturando-as.

\section{CONCLUSÕES INCONCLUSAS}

Como se vê, os conceitos jurídicos são emulações, cuja elaboração visa à manutenção do poder simbólico, instaurando uma ordem do que saber, de como saber, para que saber. Portanto, se de fato existe uma relação intrínseca da subjetividade - Política e do Direito - não existe justiça a promover, primeiro porque as decisões são derivadas de escolhas pessoais, e segundo porque ela é, em si inatingível, uma experiência do impossível, como analisou Derrida. E com isso, resta mais do que evidente que a fundação do Direito é mitológica, funcionando apenas num efeito de homologia, na reprodução das condições sociais dentro do próprio sistema jurídico.

Entretanto, é possível ser justo conforme o Direito, pois é importante desafiar o indecidível. Veja-se, se a justiça se realiza por meio de uma decisão, ficar sem decidir é abrir mão da justiça; no entanto, decidir significa limitar-se a certas regras jurídicas, o que desde logo retira toda a plenitude da justiça e mais, retira a responsabilidade e a liberdade de quem decidiu. E para superar essa questão talvez seja preciso reconhecer o 
espaço da subjetividade, pois a realização da justiça passa necessariamente pela restauração de um novo significado, como se inventasse a lei em cada caso, dando um novo frescor.

Nesse sentido, a força performativa deve ser entendida como uma garantia de que a justiça será sempre uma busca, não permitindo ser o intérprete esmagado pela generalidade de uma regra por uma exigência do direito. Ao buscar uma decisão, ainda que seja politizada, pois a própria politização é interminável, mesmo que ela não possa e não deva nunca ser total, é necessário que não deixemos o singular, a diferença, a heterogeneidade, em resumo, o indivíduo, sem ser considerado.

Talvez seja esse um caminho a ser percorrido.

\section{LAW AND SUBJETIVITY: AN ESSAY ABOUT STATE PUNISHMENT}

\section{Summary}

This paper aims to discuss judicial decisions, inquiring about subjectivity spaces of the judge when makes sentencing. The hipothesis given is positive and it is built using the criminal law institutions. But, if the hipothesis is correct is extremely necessary have mecanisms of control to protect the democratica warranty of human autonomy. The mechanism of judicial decisions is based on security and justice, values from modernity which fundaments the instrumental racionality, what by it self, legitimates dogmatic as the only tool to solve social conflicts. Nevertheless, Those promises of the modernity (security and justice) are a way of hide the subjectivity, because decisions are made by the men whom are conditioned by social relations, what means - political power and strength are not indissociable. In Criminal Law the histories of punishment and process are guided by economy and politics what leads, clearly, to the existence of subjectivity in the Law and the decisions based by laws. So, recognising the political space in the Law, authors discuss ways to help the control of the subjectivity.

Keywords: subjectivity; modernity; dogmatic; punishment history

\section{REFERENCIAS}

BAUMAN, Zygmunt. Modernidade e ambivalência. Rio de Janeiro: Zahar, 1999.

O mal-estar da pós-modernidade. Rio de Janeiro: Zahar, 1998.

BECCARIA, Cesar. Dos Delitos e das Penas. Rio de Janeiro: Martins Fontes, 2005.

BOBBIO, Norberto. O positivismo jurídico. São Paulo: ícone editora, 1995.

BERCHT Gabriela. Apontamentos sobre "do direito à justiça”em força de lei, de Jaques Derrida. Sistema Penal \& Violência, v. 2, n. 2, Porto Alegre, jul-dez, 2010.

BRASIL, Superior Tribunal de Justiça. HC 136009. Rel. Min. Laurita Vaz. DJe 25/04/2011. 
BRASIL. Superior Tribunal de Justiça. HC 121642. Rel. Min. OG FERNANDES DJe 23/08/2010.

BOURDIEU, Pierre. Poder Simbólico. 13 eds. Rio de Janeiro: Bertrand Brasil, 2010.

DE GIORGI, Alessandro. A miséria governada através do sistema penal. Rio de Janeiro: Revan, 2006.

DERRIDA, Jacques. Força de lei: o fundamento místico da autoridade. 2 ed. São Paulo: Martins Fontes, 2010.

DESCARTES, René. O discurso do método. São Paulo: Martins Fontes, 2001.

FAICLOUGH, Norman. Discurso e mudança social. Brasília: Editora UNB, 2008.

FOUCAULT, Michel. A ordem do discurso. Aula inaugural no Collège de France, pronunciada em 02 de dezembro de 1970. 2 ed. São Paulo: Edições Loyola, 2010.

A verdade e as formas jurídicas. 3 eds. Rio de Janeiro: NAU, 2009

Vigiar e punir. História da violência nas prisões. Petrópolis: Vozes, 2009.

FREITAS, Ricardo de Brito A. P. Razão e Sensibilidade: fundamentos do Direito Penal moderno. São Paulo: Juarez de Oliveira, 2001.

GIDDENS, Anthony. As consequências da modernidade. São Paulo: UNESP, 1991.

HARVEY, David. Condição pós-moderna: uma pesquisa sobre as origens da mudança cultural. 6 ed. São Paulo: Edições Loyola, 1996.

MELOSSI, Dario; PAVARINI, Massimo. Cárcere e fábrica. As origens do sistema penitenciário (séculos XVI XIX). Rio de Janeiro: Revan, 2006.

RUSCHE, G; KIRCHHEIMER, O. Punição e estrutura social. Rio de Janeiro: Revan, 2008.

SANTOS, Boaventura de Sousa. Um discurso sobre as ciências. 10 ed. Porto: Afrontamento, 1998.

SANTOS, Karla Cristina dos. Implicações da noção de sujeito na discussão da responsabilidade de fala, disponível em < http://www.filologia.org.br/ileel/artigos/artigo_424.pdf>. Acesso 25.04.2011.

VILLEGAS Mauricio García, On Pierre Bourdieu’s Legal Thought, Droit et Société, n. 56-57, p. 57-71, 2004.

WACQUANT, Löiq. O legado sociológico de Pierre Bourdieu: duas dimensões e uma nota pessoal, Revista de Sociologia Política, Curitiba, 19, p. 95-1 10, nov. 2002.

Trabalho enviado em 16 de jultho de 2015.

Aceito em 28 de setembro de 2015. 